\title{
Using educational outreach and a financial incentive to increase general practices' contribution to chlamydia screening in South-East London 2003-2011
}

Sebastian Kalwij ${ }^{1,2^{*}}$, Sarah French ${ }^{2}$, Rumbi Mugezi ${ }^{3}$ and Paula Baraitser ${ }^{4,5}$

\begin{abstract}
Background: The London Boroughs of Lambeth and Southwark have high levels of sexually transmitted infections including Chlamydia trachomatis. Modelling studies suggest that reductions in the prevalence of chlamydia infection will require a high level of population screening coverage and positivity among those screened. General practice has a potentially important role to play in delivering these levels of coverage since large numbers (up to $60 \%$ ) of young people visit their general practice every year but previous work suggests that there are barriers to delivering screening in this setting. The aim of this study was to evaluate an intervention to increase chlamydia screening in general practice within Primary Care Trusts (PCTs) of Lambeth and Southwark, a strategy combining financial incentives and supportive practice visits to raise awareness and solve problems.
\end{abstract}

Methods: Data on age, gender, venue and chlamydia result for tests on under 25 s in Lambeth from 2003-11 was obtained from the National Chlamydia Screening Programme. We analysed the number and percentage of tests generated in general practice, and looked at the number of practices screening more than $10 \%$ of their practice cohort of 15-24 year olds, male/female ratio and positivity rates across other screening venues. We also looked at practices screening less than $10 \%$ and studied change over time. We compared data from Lambeth and Southwark with London and England. We also studied features of the level and type of educational and financial incentive interventions employed.

Results: Chlamydia tests performed in general practice increased from 23 tests in 2003-4 to 4813 tests in 2010-11 in Lambeth. In Southwark they increased from 5 tests in 2003/04 to 4321 in 2010/11. In 2011, 44.6\% of tests came from GPs in Lambeth and 46\% from GP's in Southwark. In Lambeth $62.7 \%$ of practices tested more than $10 \%$ of their cohort and in Southwark this was 55.8\%. In Lambeth, postivity rate in 2010/11 was 5.8\% in men and 6.0\% in women. In Southwark positivity rate was 3.9\% in men and 5.3\% in women. In 2003/04 13\% tests in general practice (Lambeth) were from men, this increased to 25\% in 2010/11. In Southwark this increased from 20\% in 2003/04 to 27.6\% in 2010/11. We compared the results with London and national data and showed significant differences between GP testing in Lambeth and Southwark, and GP testing in London and the rest of England.

\footnotetext{
* Correspondence: sebastiankalwij@mac.com

${ }^{1}$ Amersham Vale Practice, Waldron Health Centre, London SE14 6LD, United

Kingdom

${ }^{2}$ NHS Lambeth, 1 Lower Marsh, London SE1 7NT, United Kingdom

Full list of author information is available at the end of the article
} 
(Continued from previous page)

Conclusions: General practices can be important potential providers of chlamydia tests.

With a combination of sustained support, financial incentives and feedback on performance, general practice may be able to test a large percentage of 15-24 year olds. General practice is also a potentially important provider of chlamydia tests to young men.

Keywords: Chlamydia trachomatis, Chlamydia screening, General practice, Lambeth, Southwark, Public health, STI testing

\section{Background}

The English National Chlamydia Screening Programme (NCSP) started in 2003. It aims to reduce the prevalence of chlamydia infection by offering opportunistic testing to sexually active 15-24 year olds. The London Boroughs of Lambeth \& Southwark are deprived, multiethnic boroughs with high rates of Chlamydia trachomatis and other STI's [1,2]. Chlamydia testing has been offered in almost 100 different community screening sites ranging from general practice and Community Reproductive and Sexual Health (CRSH) clinics to schools, prisons, pharmacies and websites. The Department of Health set screening targets for the period April 2008March 2011: $17 \%$ of the 15-24 yrs cohort to be tested in $2008 / 09$, rising to $25 \%$ in $2009 / 10$ and $35 \%$ in $2010 / 11$ [3]. Modelling studies suggest that reductions in the prevalence of chlamydia infection will require a level of population screening coverage and positivity among those screened that is reflected in the chlamydia diagnosis rate of 2400 per 100,000 population set out within the Public Health Outcomes Framework for England 2013-16 [4,5]. The English Public Health Outcomes Framework specifies a diagnosis rate of 2400 per 100,000 population [6].

CRSH clinics (specialist sexual health services) are well placed to offer chlamydia screening but on their own they cannot reach enough young people in the 1524 year old age group to achieve screening coverage rates sufficient to reduce chlamydia prevalence. In order to create more capacity for chlamydia screening general practice was identified as an important provider of tests [7]. GPs already provide contraception services and see a large proportion of the population: $75 \%$ of young women and $60 \%$ of young men visit their GP every year in the UK [8]. However as chlamydia screening is not part of the UK GP contract nor incorporated in the National Quality and Outcomes Frameworks for primary care it is difficult to expect GPs to take on this additional workload without support. Several studies have shown that many young people prefer to be seen and treated by their own GP with whom they are familiar rather than visiting a specialist sexual health clinic. In contrast to wide spread belief, young people see this continuity of care as an advantage [9-11] An added advantage to screening in general practice is that it can reduce embarrassment as the reason for the visit is known only by the health professional and patient. Young people prefer the offer of a test within the privacy of a consulting room rather than the test being initiated by a receptionist, where patients can be overheard [12].

Several studies have looked at ways to increase screening for chlamydia in primary care including computer reminders [13], a small financial incentives [14], workshops and regular feedback to clinicians [15-17]. Other studies have looked at ways to increase healthcare outcomes in general and the Cochrane library has a large collection of review articles regarding education outreach visits, feedback and financial incentives [18]. A Cochrane review of target payments to primary care physicians to increase immunisation rates suggested that there is insufficient evidence to provide a clear answer on whether this strategy is effective [19]. However a review of audit and feedback showed that this approach could be effective when the health professionals are not performing well to start with, where the person responsible for the audit and feedback is a colleague, where payments are provided more than once with clear targets and an action plan included [20-22]. The intervention evaluated here included a financial component, audit and feedback covering all the elements above, associated with effective behaviour change. The London Boroughs of Lambeth and Southwark adopted an approach to support testing that combined a financial incentive to test with sustained, outreach education and practice based support with audit and feedback.

\section{Method \\ The intervention \\ A financial incentive}

GPs were offered a financial incentive for testing a proportion of their 15-24 year old registered population, with targets increasing year on year. For example, a practice screening just $5 \%$ of its $15-24$ year old cohort was awarded a small payment of around $£ 100$ to $£ 500$ at financial year end, but those reaching higher targets were awarded greater sums from $£ 850$ up to $£ 2600$ (depending on practice size). The total sum of money paid out to practices in Lambeth 2010/11 was $£ 27,600$ (USD: 
43,301, Euros: 35,329). In Southwark the remuneration was more generous due to a different payment structure. Practices were paid per test according to the following sliding scale: $£ 6$ per screen under $10 \%$ of sexually active $15-24$ year old population, $£ 10$ for screening $10 \%$ and $£ 15$ for screening $15 \%$. In $2010 / 11$ the money paid to individual practices varied from $£ 6$ to $£ 6300$ for the top screening practice. The total pay out was $£ 54,566.00$ (USD 85,607, Euros: 69,649). The financial incentive scheme has been discontinued in Lambeth in October 2011 but is ongoing in Southwark.

\section{Education outreach support}

Alongside a full time chlamydia screening co-ordinator, and input from an additional primary care health promotion facilitator, Lambeth employed a local GP for 8 hours per month ( $£ 5000$ per year) from August 2005 onwards (ongoing at present) to provide an evidence based approach to supporting screening. This included: practice specific peer support; workshops on chlamydia screening; regular feedback on performance. Southwark employed a chlamydia screening coordinator from 2003, providing a similar package of support. The coordinator was available full time and combined her activities with improving screening in other community venues. All practices in Lambeth and Southwark were approached (94 in total). Some practices needed very little support and were already offering screening to their patients and were only visited once. Practices with low screening rates were offered more intense one-hour practice based workshops to identify and overcome barriers to screening and repeat visits. The team aimed to generate long term, supportive relationships with general practices, involving their staff as a group rather than individual doctors or nurses, as screening should involve every clinician, especially where staff turn-over in inner city practices is high. Regular feedback to GPs and practice managers on their practice performance was given to each practice, all practices were audited on management of their positive screens, all practices were sent newsletters and we shared league tables. Low screening Lambeth practices (those who screened less than $10 \%$ of their $15-24$ year cohort) were identified at the beginning of each financial year and were approached during the first half of this year. In the meantime we continued providing feedback to higher and midrange screening practices in order to keep these practices motivated. The same strategy was used in Southwark, which was discussed during joint quarterly meetings. In addition to this, all practices could approach the team in case of any problems.

Evaluating the impact of this intervention To evaluate this intervention we looked retrospectively at all Chlamydia tests provided by registered testing sites in Lambeth and Southwark between $1^{\text {st }}$ April 2003-31 ${ }^{\text {st }}$ March 2011. All chlamydia testing sites have a specific site code so the origin of each test could be traced back to the testing site. The National Chlamydia Screening Programme collects data from each site and these are fed back to the Chlamydia Screening Office on a quarterly basis. For each site, age and sex of the person tested and test result was available. We analysed these data for young people aged 15-24 years registered with a practice in Lambeth and Southwark (based on postcode). We excluded tests from patients who were symptomatic and patients who were tested in Lambeth or Southwark but were registered elsewhere. We compared\% of tests in General Practice with figures from London and England. We included 'Non NCSP Non GUM' data to capture the use of standard pathology test request forms instead of the NCSP request form. A typical screening year coincides with the UK tax year starting in April and ending in March the following year. During this study we therefore collected data from $1^{\text {st }}$ of April 2003 until 31 $1^{\text {st }}$ of March 2011.

We looked at the percentage of 15-24 year olds screened rather than the absolute number of patients, as practice sizes vary and bigger practices have more staff available to offer tests. National data suggests that young men are a hard to reach group so we looked at the male/ female ratio of those tested and Lambeth and Southwark and we compared these with tests done in London and England. We aimed to increase the number of practices screening more than $10 \%$ of their practice cohort as we consider this a measure of a systematic approach to screening. We also looked at individual practices in Lambeth and Southwark to evaluate our impact on improving low screening practices. We did not have this level of detail for practices in other PCT's in London or England. For this study, ethical approval was not needed as this was a service evaluation. Data has been anonymised and individual practices cannot be identified.

\section{Results}

\section{Lambeth}

Year on year there has been an increase in tests across most of the registered screening sites from 133 in 2003 to 10,803 tests in $2010 / 11$ (Figure 1). This represents $35.6 \%$ coverage of the target cohort of 30,345 young people residing in Lambeth, the highest coverage in England [3]. In the year 2010/11, $44.6 \%$ of all chlamydia tests came from general practice followed by $36.8 \%$ from the Community Reproductive and Sexual Health clinics, the first year that more tests were being offered in general practice than anywhere else. By 2010/11, 51 out of the 52 general practices in Lambeth had signed up to the Screening Programme and 124 visits by the GP champion had been completed to 52 practices. Of the 44,184 valid results for Chlamydia trachomatis reported 


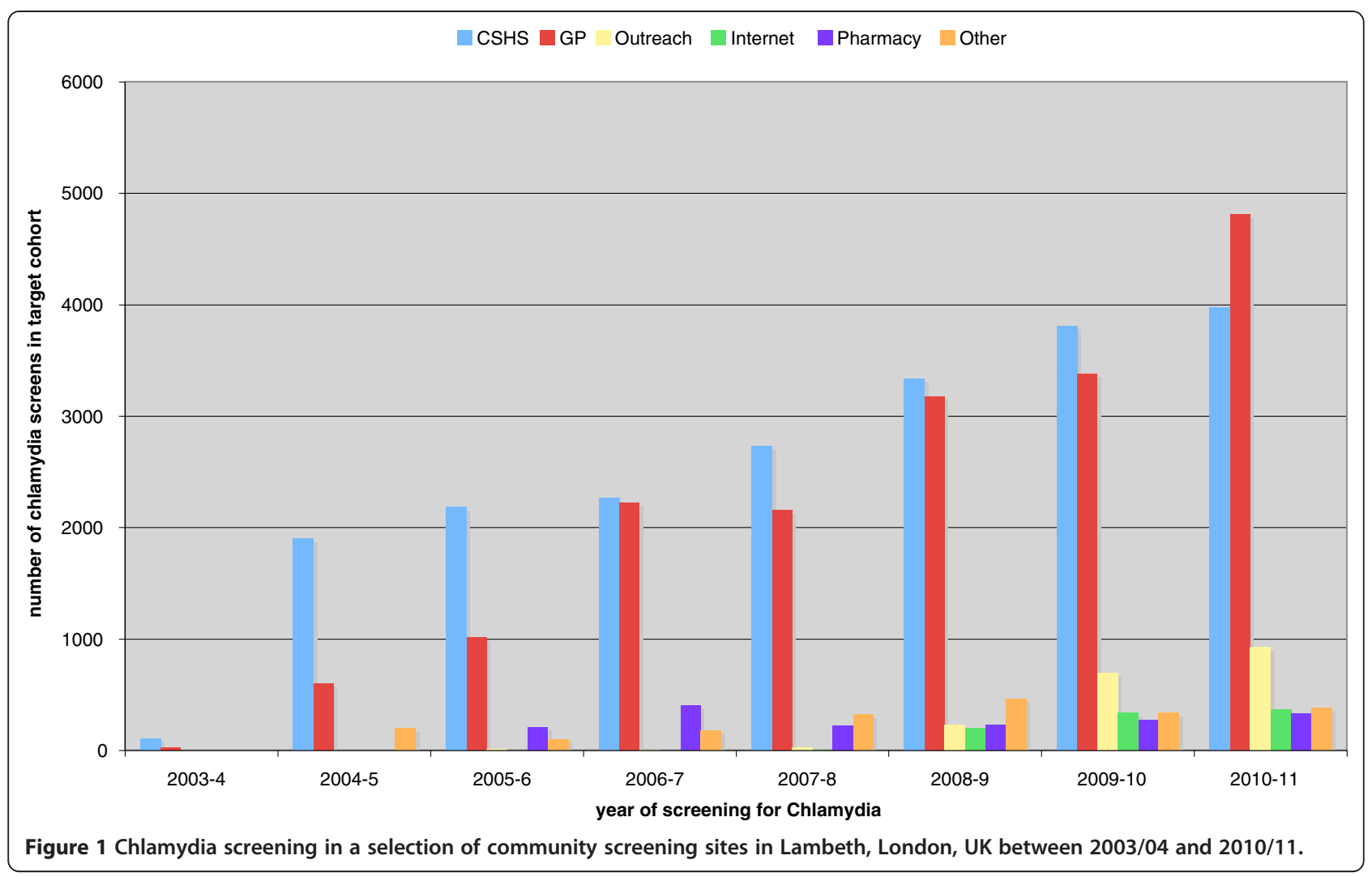

to the Lambeth Chlamydia Screening Office from $1^{\text {st }}$ April 2003-31 ${ }^{\text {st }}$ March 2011, 20,312 tests (46\%) came from the Community Reproductive and Sexual Health Clinics, 17,399 tests (39\%) from General Practice, 1898 tests (4.3\%) came from 'Outreach youth events', 1679 tests $(3.8 \%)$ came from Pharmacies, 908 tests $(2 \%)$ came from the Website (www.checkurself.nhs.net), 216 tests (0.5\%) came from midwives and 1772 tests (4\%) came from a wide variety of other screening sites, e.g. prisons and schools, but each of these sites only contributed very few tests.

The percentage of men tested in General Practice increased from $13 \%(3 / 23)$ in $2003 / 04$ to $25 \%$ (1191/ 4569) in 2010/11 in Lambeth.

With regards to low screening practices there has been an improvement in practices approached. We show the results of the 24 low screening practices in Lambeth (screening $<10 \%$ of their target population) in 2008/09 and we compared this with $2010 / 11$ as it takes time for effect to take place (Figure 2). The average screening coverage increased from $5.1 \%$ to $10.3 \% 3$ years later. One practice in particular improved from $5.6 \%$ to $33 \%$ target cohort coverage. This is the result of at least one practice visit which included a presentation and an educational session, a follow up phone call and email communications with the practice lead for chlamydia screening.

\section{Southwark}

For Southwark (Figure 3) the results are as follows: by 2010/11 all 43 general practices signed up to the chlamydia screening programme (population cohort 1524 year olds: 38310$) 41783$ valid tests from $1^{\text {st }}$ April 2003-31 ${ }^{\text {st }}$ March 2011, 25.167 tests (60.2\%) came from the Community and Reproductive Sexual Health Clinics, 13211 tests (31.6\%) from General Practice, 1816 tests (4.4\%) came from Pharmacies, 916 tests (2.2\%) came from 'Outreach youth events', and 673 tests (1.6\%) came from the website (www.checkurself. nhs.net).

The overall chlamydia positivity rate for $2010-11$ was $7.8 \%, 11.1 \%$ in CRSH clinics and $5.9 \%$ in general practice. For Southwark the population coverage for 2010/11 was: $24,5 \%$ (9401 test, cohort size: 38310 ).

With regards to low screening practices in Southwark there has been an improvement in practices approached. We show the results of the 21 low screening practices (screening $<10 \%$ of their target population) in 2008/09 and we compared this with $2010 / 11$ as it takes time for effect to take place. The average screening coverage increased from $5.7 \%$ to $12.6 \% 3$ years later. Three practices screened more than $30 \%$ of their target cohort. The percentage of men tested in General Practice in Southwark increased from from $20 \%$ to $27.6 \%$ in the period between 2003/04 and 2010/11 (Figure 4). 

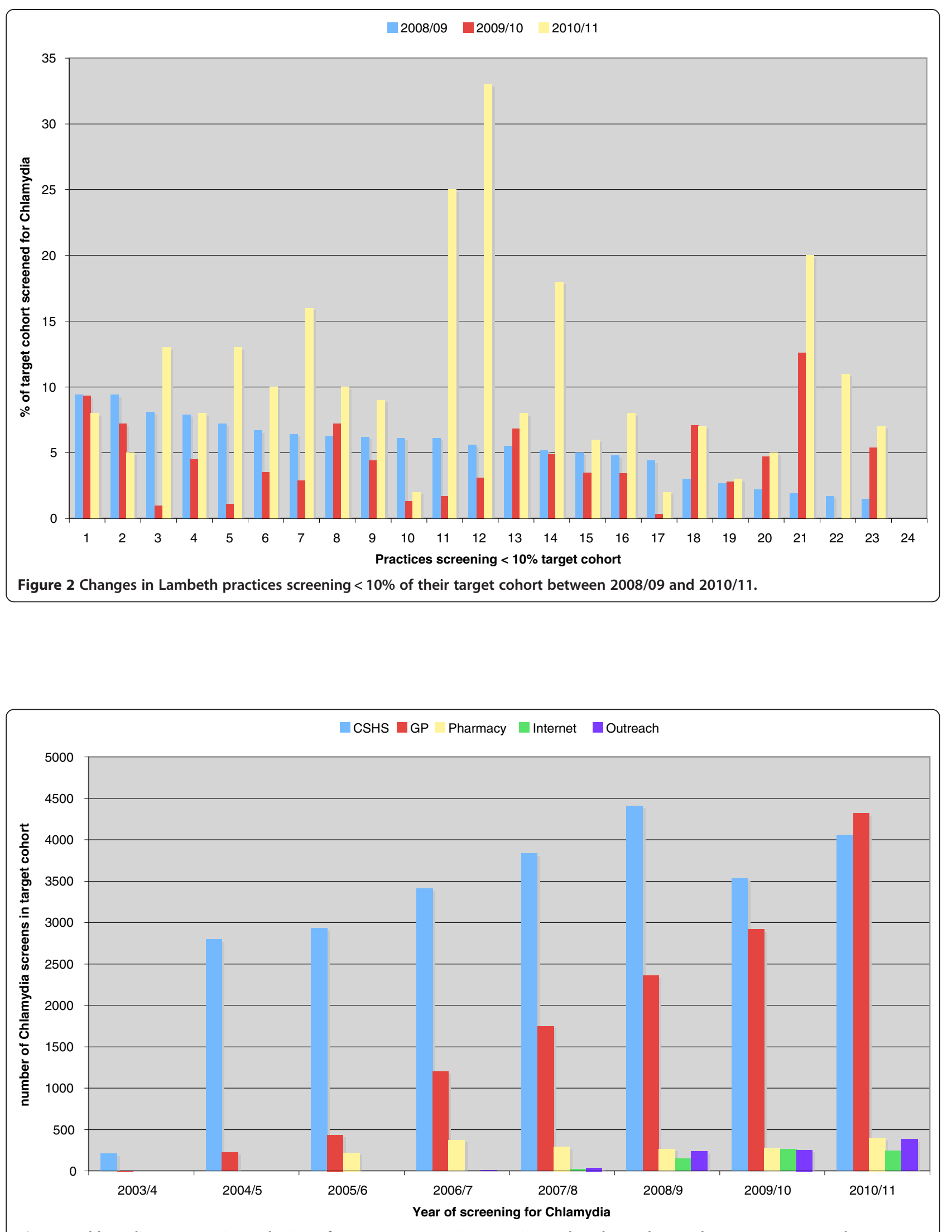

Figure 3 Chlamydia screening in a selection of community screening sites in Southwark, London, UK between 2003/04 and 2010/11. 


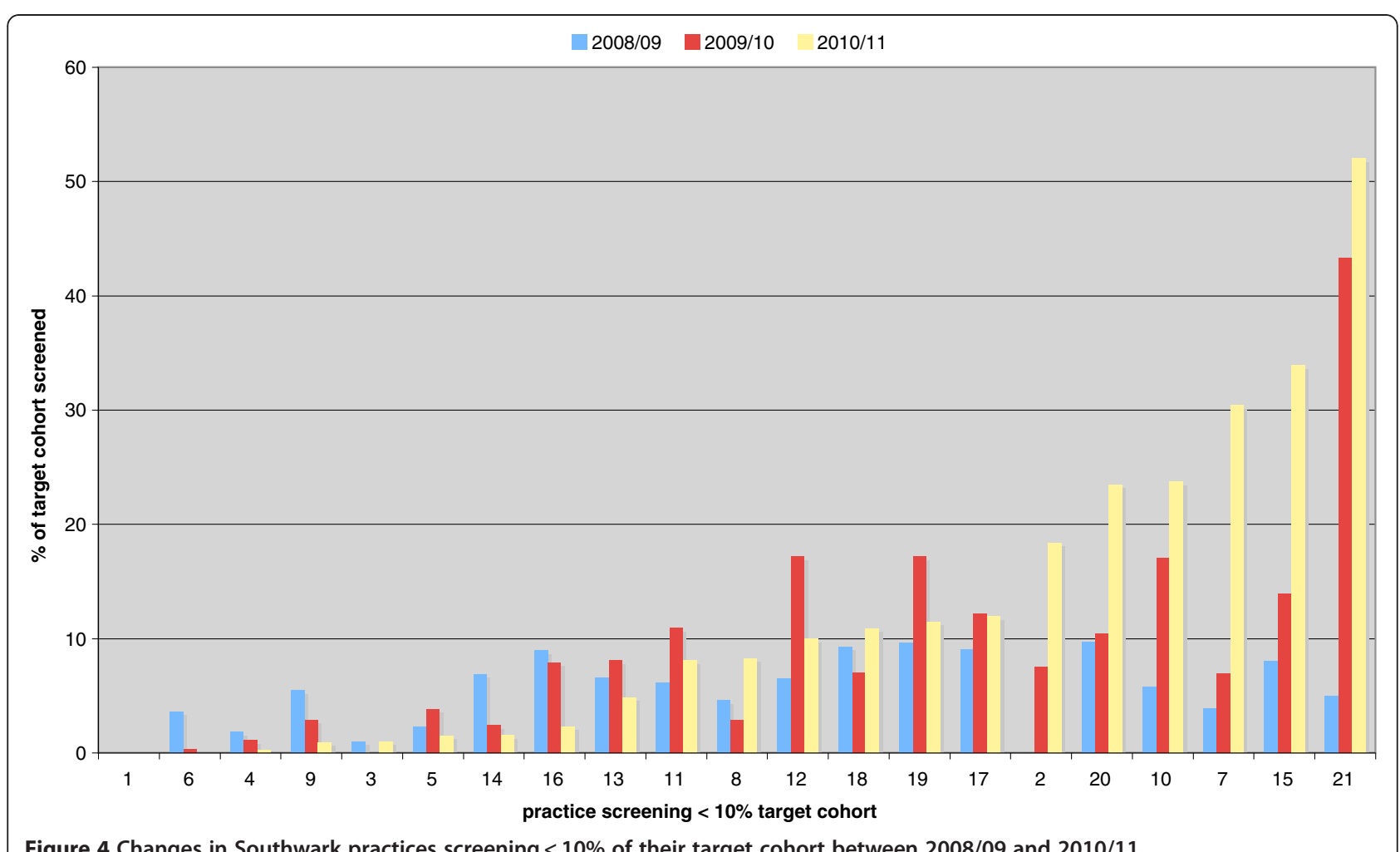

Figure 4 Changes in Southwark practices screening $<10 \%$ of their target cohort between 2008/09 and 2010/11.

In Lambeth, by the end of the year 2010/11, 44.6\% of tests came from General Practice. However there was a large variation in screening activity amongst the 51 practices. By 2010/11, 32 practices (62.7\%) reached more than $10 \%$ of their target cohort including eight screening $20-30 \%$ and four $(7.8 \%)$ screened more than 30\% (Median: $14 \%$ Mean 14\%). We saw the same variation in screens done by GPs in Southwark, where 24 out of 43 practices $(55.8 \%)$ screened more than $10 \%$ of their practice cohort and four (9.3\%) screened more than $30 \%$ of their practice cohort (Median 14\% Mean 11\%).

Testing for Chlamydia has also increased simultaneously across all community testing sites in all PCTs in England. From 2,338 tests in 2003/04 to 221,884 in 2010/11. When comparing the screening data from Lambeth and Southwark with London and national levels it shows that the percentage of chlamydia tests coming from general practice are significantly greater in Lambeth and Southwark $(\mathrm{p}<0.01)$ (Figure 5).

In order to intervene effectively to support an increase in GP screening we identified some common barriers from the outset: 1 . Simple practical barriers such as lack of test request forms or test kits, or needing to be shown how to use the computer alerts and templates; 2 . A lack of confidence in offering tests in non-sexual health consultations; 3. Some practices did not engage with chlamydia screening as this was deemed to be outside the realm of primary care and those GPs sign-posted patients to local specialist clinics instead, one Lambeth practice opted out of the Chlamydia Screening Programme after several years of failing to improve screening uptake.

\section{Discussion}

We have shown that it is possible to achieve a high chlamydia screening coverage of the 15-24 year population cohort by involving general practice in addition to the CRSH. GPs are well placed to treat and manage patients who test positive for chlamydia as part of a package of holistic sexual health care.

Thus this study describes a successful implementation of a combined strategy for chlamydia screening at PCT level involving 94 practices. It is notable that it appeared to make no difference whether sustained support for screening was provided by a fellow general practitioner or a dedicated chlamydia screening co-ordinator. In both cases the combination of a financial incentive plus support seemed to generate similar increases in testing. It is important to add to this that the Lambeth GP only spent 8 hours per month liaising with practices whilst the chlamydia screening coordinator was in a full time post.

With regards to the potential influence of financial incentive in both PCTs. Lambeth interventions seem to have achieved greater impact with lower financial outlay.

It is important to note that both PCTs achieved high community coverage partly because all GP practices except one were participating (94 out of 95 practices) in 


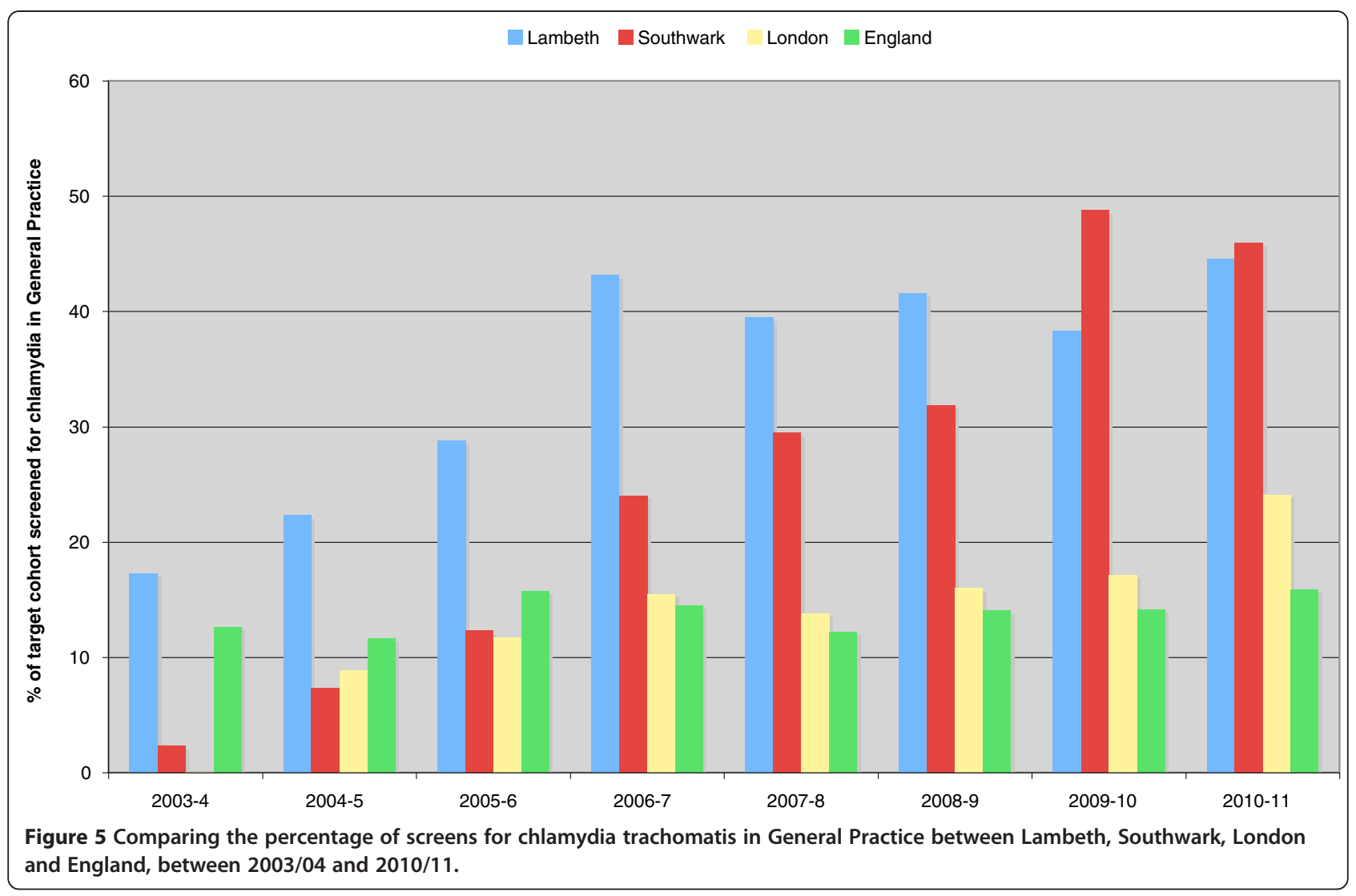

screening. During the first years of the programme (2003-2008) efforts were made to get all practices involved, and in the later stages, efforts were focused on increasing the percentage of 15-24 year olds screened in each practice. Most PCTs have not achieved such widespread GP coverage.

Figures 1 and 5 show that the whilst the number of patients screened for chlamydia in Lambeth increased year after year (Figure 1), the proportion of tests coming from general practice has tailed off (Figure 5). This may in part be related to a simultaneous increase in CRSH capacity. For example, a Lambeth CRSH clinic was remodelled with increased access hours in an area where some GPs were not offering tests routinely. Many GPs sign-post patients to this new clinic, instead of improving their own services. Whilst the number of tests increased in General Practice, it increased even further in the new CRSH.

With regards to variation in screening rates per practice, in both PCTs, our experience suggests factors explaining the wide variation in screening may include the motivation of clinical staff, having a practice lead regularly monitoring screening activity, responding to computer reminders, offering open access young people clinics, and having doctors and nurses experienced at sexually transmitted infection (STI) management. There was no clear link between smaller practices or larger health centres in offering screening for chlamydia, but smaller practices were quicker to agree to take on screening than larger practices. It is also suggested that repeat practice feedback saw a bigger increase in testing numbers in the mid-range screening practices than in those who tested very few patients, but this observation needs further study, currently underway. Much of our work has concentrated on improving screening rates in low screening rates and some success has been observed (Figures 2 and 4). Meanwhile, some high screening practices are not able to maintain high levels of screening year after year. It is important that when focusing on the low screening practices, not to forget about the high screening practices.

\section{Limitations}

As a service evaluation study, a number of factors operating alongside those interventions explored could have had an impact on local screening activity. Early in 2010 a large, national media campaign was launched, focusing on chlamydia and other STI testing. This awareness raising campaign is likely to have had a confounding effect on the number of patients being tested in Lambeth and Southwark.

We assumed for the purposes of comparative analysis, that each screen equates to one patient, and that most patients were only screened once per year. Our service 
data collection did not enable us to assess separately the number of tests per patient per year.

Both the level of support in both PCTs and the level of remuneration have not been the same from the start and therefore this will present as a confounding factor.

Southwark GPs received higher levels of financial incentive and this may have motivated some of these more so than the smaller incentives provided to Lambeth practices.

It has been observed that whilst the GP only worked for $8 \mathrm{~h}$ per month it was easier and quicker to gain access to colleagues. This peer support may have had a different impact on screening levels than the support given by the chlamydia screening coordinator but who had more time to support practices. It is important to realise that the service we evaluated in this paper has not been set up as a research project, it's a real time chlamydia screening programme and was subject to national guidelines and targets as set out by the NCSP.

As we chose a multi faced approach it is difficult to distinguish which part of the intervention may have had the most impact. We may be able to evaluate this in more detail in future years. Chlamydia screening will continue in both PCTs though practices in Lambeth no longer receive a financial incentive but will get ongoing support by a GP for $8 \mathrm{~h}$ per month. In Southwark however, the present level of remuneration will continue but the support from a chlamydia screening coordinator has been discontinued in both PCTs in response to changes in the national chlamydia screening strategy.

Over the years many PCTs around London and England have shown an interest in the Lambeth and Southwark model, some PCT's implementing a similar approach. We are not aware of other PCTs using these interventions consistently for the same length of time. It is therefore difficult to compare Lambeth and Southwark with different PCTs at this level of intervention detail.

\section{Conclusions}

General practitioners are important potential providers of chlamydia tests.

With this study we have demonstrated that with a combination of sustained support, financial incentive and feedback, general practice may be able to test a large percentage of the 15-24 year olds in the community. General practice is also a potentially important provider of chlamydia tests to young men - a group that has been difficult to engage with the national chlamydia screening programme. A number of variable features within practices such as sustained clinician leadership may also have contributed to the levels of success alongside the combined intervention approach.

\section{Abbreviations}

CRSH: Community reproductive and sexual health; GP: General practice, General practitioner (= Primary Care Physician); LES: Local enhanced service; NCSP: National chlamydia screening programme; PCT: Primary care trust; QOF: Quality and outcome framework; STI: Sexually transmitted infection; UK: United Kingdom.

\section{Competing interests}

SK works as a GP for the Chlamydia Screening Programme for Lambeth PCT. PB is the medical advisor for the NCSP, SF is the sexual health facilitator for Lambeth PCT. RB worked as the Chlamydia Screening Officer in Southwark $P C T$. Lambeth PCT has agreed to pay for the article processing charges. There are no other competing interests.

\section{Authors' contributions}

SK initiated writing up the article and provided the first draft. SF and RM were part of the Chlamydia Screening Programme Lambeth and played part in collecting the data and improving the programme. SK, PB RM and SF contributed in writing and reviewing the article. All authors read and approved the final manuscript.

\section{Acknowledgments}

Alireza Talebi, Information Systems Manager from the National Chlamydia Screening Programme for providing the data for this study, Adrian Kalwij from Utrecht University, the Netherlands, for the statistical analysis, Dr Pippa Oakeshott for her valuable contributions during the writing stage of the article. All Lambeth and Southwark general practitioners and practice nurses for providing all the chlamydia tests and the staff of Lambeth and Southwark PCT who have been working on the chlamydia screening programme, in particular Jess Peck and Emma Robinson, public health consultant.

\section{Author details}

${ }^{1}$ Amersham Vale Practice, Waldron Health Centre, London SE14 6LD, United Kingdom. ${ }^{2} \mathrm{NHS}$ Lambeth, 1 Lower Marsh, London SE1 7NT, United Kingdom. ${ }^{3}$ Guys and St Thomas Community Health Services, Mawbey Health Centre, 39 Wilcox Close, London SW8 2UD, UK. ${ }^{4}$ Kings College Hospital NHS Foundation Trust, 100 Denmark Hill, London SE5 9RS, UK. ${ }^{5}$ National Chlamydia Screening Programme, Health Protection Services - Colindale, Health Protection Agency, 61 Colindale Avenue, London NW9 5EQ, UK.

Received: 20 May 2012 Accepted: 14 September 2012

Published: 18 September 2012

\section{References}

1. Low N: Phase specific strategies for the prevention, control, and elimination of sexually transmitted infections: case study in Lambeth, Southwark, and Lewisham, London, UK. Sex Transm Infect 2002, 78:i133-i138.

2. HPA: http://profiles.hpa.org.uk/IAS/dataviews/report/fullpage? viewld=38\&reportld=37\&indicator=i365\&date $=2010$.

3. NCSP: www.chlamydiascreening.nhs.uk.

4. Dorey MD, Choi YH, Soldan K, Vynnycky: Modelling the effect of Chlamydia trachomatis testing on the prevalence of infection in England: what impact can we expect from the National Chlamydia Screening Programme? Sex Transm Infect, doi:10.11.

5. Turner KME, Adams EJ, LaMontagne DS, Emmett L, Baster K, Edmunds WJ: Modelling the effectiveness of chlamydia screening in England. Sex Transm Infect. 2006, 82:496-502.

6. Department of Health: http://www.dh.gov.uk/prod_consum_dh/groups/ dh_digitalassets/@dh/@en/documents/digitalasset/dh_132559.pdf.

7. Pimenta JM, Catchpole M, Rogers PA, Hopwood J, Randall S, et al: Opportunistic screening for genital chlamydia infection. II: Prevalence among healthcare attenders, outcome, and evaluation of positive cases. Sex Transm Infect 2003, 79:22-27.

8. Salisbury $C$, et al: Opportunistic and systematic screening for Chlamydia: a study of consultations by young adults in general practice. $\mathrm{Br} J \mathrm{Gen}$ Pract 2006, 56(523):99-103.

9. Heritage J, Jones M: A study of young peoples' attitudes to opportunistic Chlamydia testing in UK general practice. Reprod Health. 2008, 5:11.

10. Balfe M, Brugha R, O'Connell E, McGee H, O'Donovan: Where do young Irish women want Chlamydia screening services to be set up? A 
qualitative study employing Goffman's impression management framework. D. Health Place 2010, 16(1):16-24.

11. Pavlin NL, Parker R, Fairley CK, Gunn JM, Hocking J: Take the sex out of STI screening! Views of young women on implementing Chlamydia screening in General Practice. BMC Infect Dis. 2008, 8:62.

12. Hogan AH, Howel-Jones RS, Pottinger E, Wallave LM, McNulty CA: ". . they should be offering it': a qualitative study to investigate young peoples' attitude towards chlamydia screening in GP surgeries. BMC Public Health 2010, 10:61.

13. Walker J, Fairley CK, Walker SM, Gurrin LC, Gunn JM, Pirotta MV, Carter R, Hocking JS: Computer reminders for Chlamydia screening in general practice: a randomized controlled trial. Sex Trans Dis. 2010, 37(7):445-50.

14. Bilardi JE, Fairley CK, Temple-Smith MJ, Pirotta MV, McNamee KM, Bourke S, Gurrin LC, Hellard M, Sanci LA, Wilss MJ, Walker J, Chen MY, Hocking JS: Incentive payments to general practitioners aimed at increasing opportunistic testing of young women for chlamydia: a pilot cluster randomized controlled trial. BMC Public Health 2010, 10:70

15. McNulty CA, et al: Interactive workshops increase Chlamydia testing in primary care-a controlled study. Fam Pract. 2008, 25(4):279-86.

16. Guy R, Ali H, Liu B, Poznanski S, Ward J, Donovan B, Kaldor J, Hocking J: Efficacy of interventions to increase the uptake of chlamydia screening in primary care: a systematic review. BMC Infectious Diseases 2011, 11:211.

17. Verhoeven V, Avonts D, Vermeire E, Denaene L, Van Royen P: A short educational intervention on communication skills improves the quality of screening for Chlamydia in GP's in Belgium: a randomized controlled trial. Patient Educ Couns 2005, 571:101-5.

18. Cochrane library. http://epoc.cochrane.org.

19. Giuffrida A, Gosden T, Forland F, Kristiansen I, et al: Target payments in primary care: effects on professional practice and health care outcomes. Editorial group. Cochrane Effective Practice and Organisation of Care Group; 2009. doi:10.1002/14651858.CD000531.

20. O'Brien MA, Rogers $S$, Jamtvedt G, Oxman AD, Odgaard-Jensen J, Kristoffersen DT, Forsetlund L, Bainbridge D, Freemantle N, Davis D, Haynes RB, Harvey E: Educational outreach visits: effects on professional practice and health care outcomes. Cochrane Database of Systematic Reviews 2007 (4). 10.1002/14651858.CD000409.pub2.

21. Scott A, Sivey P, Ait Ouakrim D, Willenberg L, Naccarella L, Furler J, Young D: The effect of financial incentives on the quality of health care provided by primary care physicians. Cochrane Database of Systematic Reviews. Issue 9th edition. 2011. doi:10.1002/14651858.CD008451.pub2. Art. No.: CD008451.

22. Flodgren G, Parmelli E, Doumit G, Gattellari M, O'Brien MA, Grimshaw J, Eccles MP: Local opinion leaders: effects on professional practice and health care outcomes. Cochrane Database of Systematic Reviews. Issue 8th edition. 2011. doi:10.1002/14651858.CD000125.pub4. Art. No.: CD000125.

doi:10.1186/1471-2458-12-802

Cite this article as: Kalwij et al:: Using educational outreach and a financial incentive to increase general practices' contribution to chlamydia screening in South-East London 2003-2011. BMC Public Health 2012 12:802

\section{Submit your next manuscript to BioMed Central and take full advantage of:}

- Convenient online submission

- Thorough peer review

- No space constraints or color figure charges

- Immediate publication on acceptance

- Inclusion in PubMed, CAS, Scopus and Google Scholar

- Research which is freely available for redistribution 